\title{
Éduquer un roi ou l'histoire d'une modification progressive du projet pédagogique pour Louis XV (1715-1722)
}

Educating a king or the history of a gradual shift in the educational plan for Louis XV (1715-1722)

Die Erziehung eines Königs, oder die Geschichte der schrittweisen Umwandlung der Erziehungsziele für Ludwig XV. (1715-1722)

Educar a un rey o la historia de una modificación progresiva del proyecto pedagógico para Luis XV (1715-1722)

\section{Pascale Mormiche}

\section{(2) OpenEdition}

\section{Journals}

Édition électronique

URL : https://journals.openedition.org/histoire-education/2411

DOI : 10.4000/histoire-education.2411

ISSN : 2102-5452

Éditeur

ENS Éditions

Édition imprimée

Date de publication : 1 octobre 2011

Pagination : $17-47$

ISBN : 978-2-84788-360-2

ISSN : 0221-6280

\section{Référence électronique}

Pascale Mormiche, «Éduquer un roi ou l'histoire d'une modification progressive du projet pédagogique pour Louis XV (1715-1722) », Histoire de l'éducation [En ligne], 132 | 2011, mis en ligne le 01 octobre 2013, consulté le 20 mai 2021. URL : http://journals.openedition.org/histoire-education/2411 ; DOI https://doi.org/10.4000/histoire-education.2411 


\section{Éduquer un roi ou l'histoire d'une modification progressive du projet pédagogique pour Louis XV (1715-1722)}

\section{Pascale MORMICHE}

En septembre 1715, à la mort de Louis XIV, s'annonce une période difficile et une des tâches les plus lourdes du royaume : éduquer le jeune roi ${ }^{1}$. À cette date, la période d'éducation de Louis XV n'a pas encore commencé : il a cinq ans et ne " passera aux hommes " qu'en 1717. Le terme de son éducation et de la régence est fixé à l'année de ses quatorze ans, lorsqu'il deviendra majeur, en février $1723^{2}$. On le sait, un roi jeune et donc une régence longue sont deux

1 Pour une vision générale des éducations princières et des derniers travaux en histoire de l'éducation en France à l'époque moderne, outre les indications bibliographiques données en introduction du présent numéro, on se reportera à Roberta Blazarini et al. (dir.), Segni d'infanzia. Crescere come re nel Seicento, coll. Storia dell'educazione, Milan, Franco Angeli, 1991; Monica Ferrari, La paideia del sourano, Florence, La Nuova Italia, 1996; Catherine Volpilhac-Auger, Gérard Luciani (dir.), L'institution du prince au XVIII ${ }^{e}$ siècle, Ferney-Voltaire, Centre international d'étude du XVIII ${ }^{e}$ siècle, 2003; Frédérique Lachaud, Ludivine Scordia (dir.), Le Prince au miroir de la littérature politique de l'Antiquité aux Lumières, Rouen, Publications des universités de Rouen et du Havre, 2007; Pascale Mormiche, Devenir prince, l'éducation des princes français, XVII ${ }^{e}-X V I I I^{e}$ siècles, Paris, CNRS Éd., 2009; Francois Cadilhon, Michel Combet, Marguerite Figeac-Monthus (dir.), Construire l'éducation de l'Ancien régime à nos jours, Bordeaux, Presses universitaires de Bordeaux, 2009; Juliane Jacobi, Jean-Luc Le Cam, Hans-Ulrich Musolff (dir.), Vormoderne Bildungsgänge. Selbst- und Fremdbeschreibungen in der Frühen Neuzeit, Beiträge zur Historischen Bildungsforschung, vol. 41, Cologne, Böhlau, 2010; Mélanges de l'École française de Rome, "Il posto dei bambini Infanzia ed età adulta tra Medioevo ed età contemporanea”, Rome, École française de Rome, 2012.

2 La régence est prévue du $1^{\mathrm{er}}$ septembre 1715 au 15 février 1723, date-anniversaire de Louis XV. Elle devait durer huit ans soit autant que celle de Louis XIV. 
facteurs importants de troubles, ce qui rend particulièrement délicat le choix d'hommes fiables et compétents, alors qu'on doit aussi tenir compte de l'équilibre des factions à la Cour.

C'est Louis XIV lui-même qui avait commencé à choisir ces hommes pour éduquer son successeur, en même temps qu'il avait donné la forme et la composition de la Régence. Acte pédagogique et acte politique avaient été mûrement réfléchis entre 1712 et le 25 août 1715 . C'est la troisième équipe que Louis XIV forme alors pour ses successeurs ${ }^{3}$. Il lui faut tenir compte de la hiérarchie traditionnelle des emplois d'éducation. Et Louis XIV entérine deux choix, d'abord une application de la configuration traditionnelle de l'équipe d'éducation, mais aussi le choix des hommes chargés de transmettre plutôt que d'innover, afin de conserver un certain type de monarchie. Cependant, Louis XIV a peu d'illusions sur la postérité de son projet.

À la mort du roi, toute la Cour s'agite dans l'attente des nominations, alors que les ambitions politiques et personnelles se révèlent au grand jour. Les enjeux sont de taille pour les courtisans : accompagner un roi depuis l'enfance permet d'obtenir un emploi sa vie durant. Les cabales de Cour cherchent à se nuire les unes les autres, ce que font parfaitement le Régent et M. de Fréjus (André Hercule de Fleury) qui deviendra le précepteur et ministre du royaume de 1726 à 1743. L'opinion commune veut qu'ils en aient tous deux profité. Nous voudrions pourtant montrer que, malgré cette accusation, ils ont surtout organisé une transition différente de celle souhaitée par Louis XIV et qui aurait été impossible avec les hommes choisis. Cette transformation conserve dans certains cas les apparences, les brutalise parfois et, plus important, modifie en profondeur la nature de ce qui est enseigné au jeune roi. Cette réorientation qui fut progressive, est évidemment une manière de s'affranchir des dernières volontés du vieux roi et d'imprimer sa marque sur le règne à venir, mais on pourrait aussi l'envisager comme une façon de perpétuer un système rigide, en procédant aux indispensables adaptations ${ }^{4}$. Enfin, le problème de l'orientation à donner à l'éducation du roi est d'autant plus complexe que se greffent sur ces questions de transmission de valeurs et d'emploi, deux autres problèmes non résolus : le conflit religieux latent et la question des princes légitimés.

3 Après l'éducation du grand dauphin et du duc de Bourgogne, dauphins successifs qui n'ont pas régné.

4 Cette question est évoquée sur le plan politique par Alexandre Dupilet, La régence absolue, Philippe d'Orléans et la polysynodie (1715-1718), Seyssel, Champ Vallon, 2011. 
Deux points seront successivement traités : établir la distribution des emplois traditionnels à la mort de Louis XIV puis, en suivant le déroulement chronologique de l'éducation de Louis XV et en s'interrogeant sur la fin abrupte, en 1722, du manuel rédigé par le précepteur A. H. de Fleury, l'Abrégé de l'histoire de France, montrer la réorganisation progressive de l'éducation de Louis XV sous le contrôle du Régent.

\section{I - Un dispositif éducatif pensé par Louis XIV}

\section{1 - Les enjeux politiques et dynastiques des emplois d'éducation}

Plantons d'abord le décor des emplois politiques liés à l'éducation, avant de faire entrer en scène les emplois quotidiens d'éducation et de service, tous susceptibles de faveurs et de renvois.

La particularité de la régence de Louis XV est d'être la première régence sans mère et sans noyau familial proche. Louis XIV a parfaitement conscience de la situation difficile dans laquelle le futur roi se trouvera, sans parents ni grands-parents, configuration qui ne s'est pas présentée depuis longtemps. "Le roi fut attaqué par des coups bien plus sensibles, son cœur, que lui-même avoit comme ignoré jusqu'alors, par la perte de cette charmante dauphine, son repos, par celle de l'incomparable dauphin, sa tranquillité sur la succession à la couronne, par la mort de l'héritier huit jours après et par l'âge et le dangereux état de l'unique rejeton de cette précieuse race ${ }^{5}$.

Qui faut-il placer autour du jeune Louis? La tradition veut que le roi-enfant ait à son service une dizaine de grands emplois précisément hiérarchisés. Louis XIV doit placer tous ses fils et neveux en fonction de la hiérarchie des princes royaux. La famille élargie dans laquelle la concurrence est vive renforce les risques de conflit. " Les plus vieux des princes de sang qui restèrent n'avoient alors tout au plus dix-sept ans ${ }^{6}$, dit d'ailleurs en se trompant Saint-Simon. La préséance des rangs doit, bien sûr, correspondre à celles des emplois en tenant compte des ambitions de chacun. Au sommet de la hiérarchie des emplois d'éducation, se trouvent les emplois politiques réservés aux princes royaux. Les fils de France et princes de sang peuvent prétendre aux charges de surintendant de l'éducation, à celles de la Maison civile et de la Maison militaire du roi et à la

5 Louis de Rouvroy duc de Saint-Simon, Mémoires complets et authentiques du duc de Saint-Simon sur le siècle de Louis XIV et la Régence, Adolphe Cheruel (éd.), Paris, Hachette, 1908, t. VIII, p. 169.

6 Idem. 
direction du pouvoir politique. Aux ducs et pairs s'ouvrent les emplois de gouverneur du roi, de la direction de la Chambre, de la Garde du roi et de ministre. À la noblesse sont destinés les emplois de sous-gouverneur, le service de la Garde-robe ou de la Chambre. Louis XIV doit enfin faire coïncider les emplois avec les hommes disponibles. Or, il reste quatre places pour quatre princes ${ }^{7}$.

Tableau 1 : la hiérarchie des rangs à la fin du règne de Louis XIV

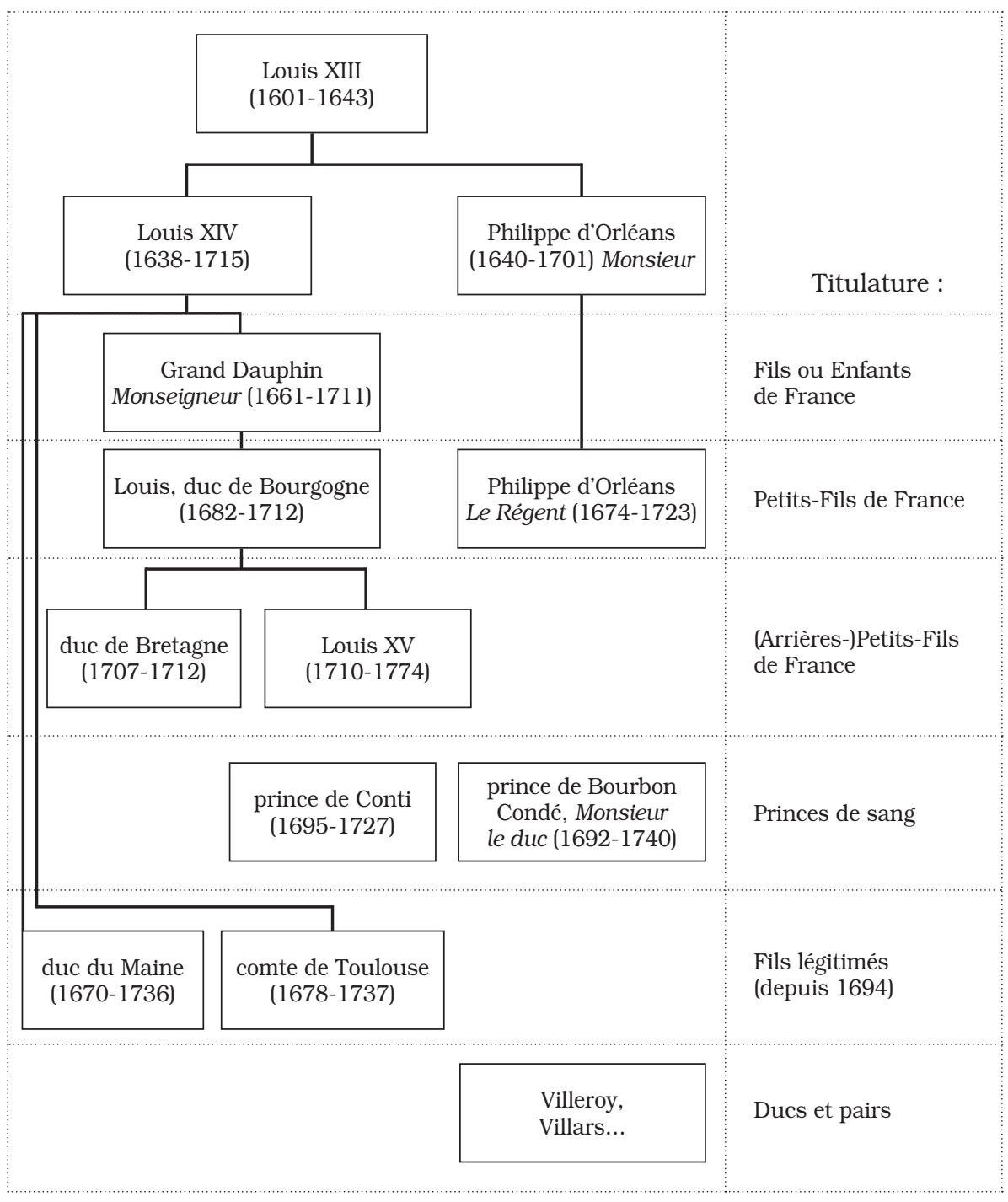

$7 \quad$ Olivier Chaline, L'année des quatre dauphins, Paris, Flammarion, 2009. 
Afin d'assurer un rang à ses fils légitimés, (le duc du Maine et son frère le comte de Toulouse), Louis XIV a, l'année précédant sa mort, modifié la hiérarchie familiale et nobiliaire ${ }^{8}$. Il entend assurer un emploi à ceux à qui va son affection discrète : "Les derniers temps [de Louis XIV] n’ont été principalement occupés qu'à consolider [la grandeur de ses bâtards] en les rendant puissants et redoutables. L'Amirauté, l'Artillerie, les carabiniers, tant de troupes et de régiments particuliers, les Suisses, les Grisons, la Guyenne, le Languedoc, la Bretagne en leurs mains les rendaient déjà assez considérables, jusqu'à la charge de grand veneur, pour leur donner de quoi plaire et amuser un jeune roi " ${ }^{9}$, s'indigne Saint-Simon.

En 1715, le duc du Maine est chargé par Louis XIV de veiller à l'éducation du jeune roi. "Ce qui nous engage à pourvoir à sa tutelle, à l'éducation de sa personne, et à former pendant la minorité un conseil de régence capable [...] de conserver le bon ordre dans le gouvernement de l'État [...]. Voulons que la personne du roi mineur soit sous la garde et la tutelle de la régence, mais il est nécessaire que, sous l'autorité de ce conseil, quelque personne d'un mérite universellement reconnu et distingué par son rang soit particulièrement chargé de veiller à la sûreté, conservation et éducation du roi mineur, nous nommons le duc du Maine pour avoir cette autorité [...] il a toute autorité sur les officiers de la Maison du jeune roi et sur les troupes qui la composent " ${ }^{10}$.

Louis XIV prévoit une structure comparable à celle qui avait été la sienne en 1643, tout en séparant la régence politique de la tutelle du roi mineur. La " surintendance de l'éducation " ainsi confiée au duc du Maine n’est pas une institution nouvelle. Sous les Valois, celui qui l'exerçait de fait était nommé le gouverneur. Le Conseil de régence tenu en 1610 pour Louis XIII ne l'avait pas mis en place, car la minorité de celui-ci ne devait durer que trois ans. Lors de la minorité de Louis XIV, la surintendance fut ajoutée et attribuée à Mazarin qui domina ainsi gouverneur et précepteur. Le terme de surintendant n'apparaît cependant pas dans le testament de 1715, afin d'éviter toute analogie avec Mazarin.

Le duc du Maine est donc " particulièrement chargé de la sûreté, conservation et éducation " du roi mineur, avec commandement des troupes de sa

8 Après leur avoir donné une place éminente au-dessus des pairs de France, il modifie encore la titulature après la mort du duc de Berry, dernier petit-fils de France, en mai 1714. Par un édit de juillet 1714, il les proclame aptes à succéder à la couronne. Et plus encore, par une déclaration du 23 mai 1715, il leur confère la qualité de princes de sang dont ils ont les honneurs depuis 1711 .

9 Saint-Simon, éd. Cheruel, op. cit., t. VIII, p. 172.

10 Baron de Breteuil, Mémoires, Evelyne Lever (éd.), Paris, F. Bourin, 1992, p. 340-342. 
Maison militaire et autorité en matière éducative sur le gouverneur Villeroy et surtout sur le duc d'Orléans. Il obtient des pouvoirs importants afin de protéger physiquement le jeune roi. Les souvenirs de la Fronde incitent en effet Louis XIV à exiger que l'enfant soit mis en sécurité au fort de Vincennes. Louis XIV voulait réellement " étendre nos soins paternels à prévoir et prévenir autant qu'il dépend de nous, les maux dont notre royaume pourrait être troublé si notre décès arrive avant que le dauphin [...] ait atteint sa quatorzième année ${ }^{11}$.

La nomination du duc du Maine et de Villeroy réjouit ceux que l'on a appelés la "Vieille Cour ", c'est-à-dire les personnages âgés et conservateurs de l'entourage du roi, dont l'élément fédérateur est Madame de Maintenon, entourée des Rohan et des Noailles. En cas de décès, le testament de 1715 prévoit que le comte de Toulouse et le duc d'Harcourt ou de Chârost (gendre de Villeroy) leur seraient substitués.

Le duc de Bourbon, dit Monsieur le duc, et les ducs et pairs s'étranglent de rage devant cette disposition qu'ils jugent exorbitante, mécontentement relayé par la plume de Saint-Simon ${ }^{12}$. Après la mort des dauphins successifs, Monsieur le duc est en effet passé du $7^{\mathrm{e}}$ rang des prétendants à la Couronne à celui de $3^{\mathrm{e}}$ prince du sang. Or, dans l'organigramme prévu par Louis XIV, il est sous les ordres du duc du Maine, comme chef de la maison civile du roi. Plusieurs fois, devant sa réprobation, le Régent le mettra en garde : "Le Régent a dit au duc de Bourbon de se modérer à l'égard des princes bâtards, ne pouvant compter sur une décision durant la minorité " ${ }^{13}$. Trop soucieux de favoriser ses fils légitimés, Louis XIV transmet donc un système riche de conflits et de contradictions que la régence s'efforce de résoudre dans les mois qui suivent.

11 Testament de Louis XIV lu au parlement le lundi 2 septembre 1715, Baron de Breteuil, Mémoires..., op. cit., p. 340.

12 " Il faut le répéter : par ce dernier acte, toute la maison civile et militaire du roi était totalement et uniquement soumise au duc du Maine et sous lui au maréchal de Villeroy, indépendamment et privativement à M. le duc d'Orléans de façon qu'il n'en pouvoit être reconnu ni obéi en rien, mais les deux chefs de l'éducation en toutes choses qui devenoient par-là les maitres de Paris et de la cour et le régent livré entre leurs mains sans aucune sûreté ". Saint-Simon, Mémoires, éd. Cheruel, op. cit., tome VIII, p. 175.

13 Jean Buvat, Gazette de la Régence, janvier 1715-juin 1719, Paris, Charpentier, 1887, février 1716, p. 72 . 
Tableau 2 : Le dispositif et les hommes prévus par Louis XIV en 1715

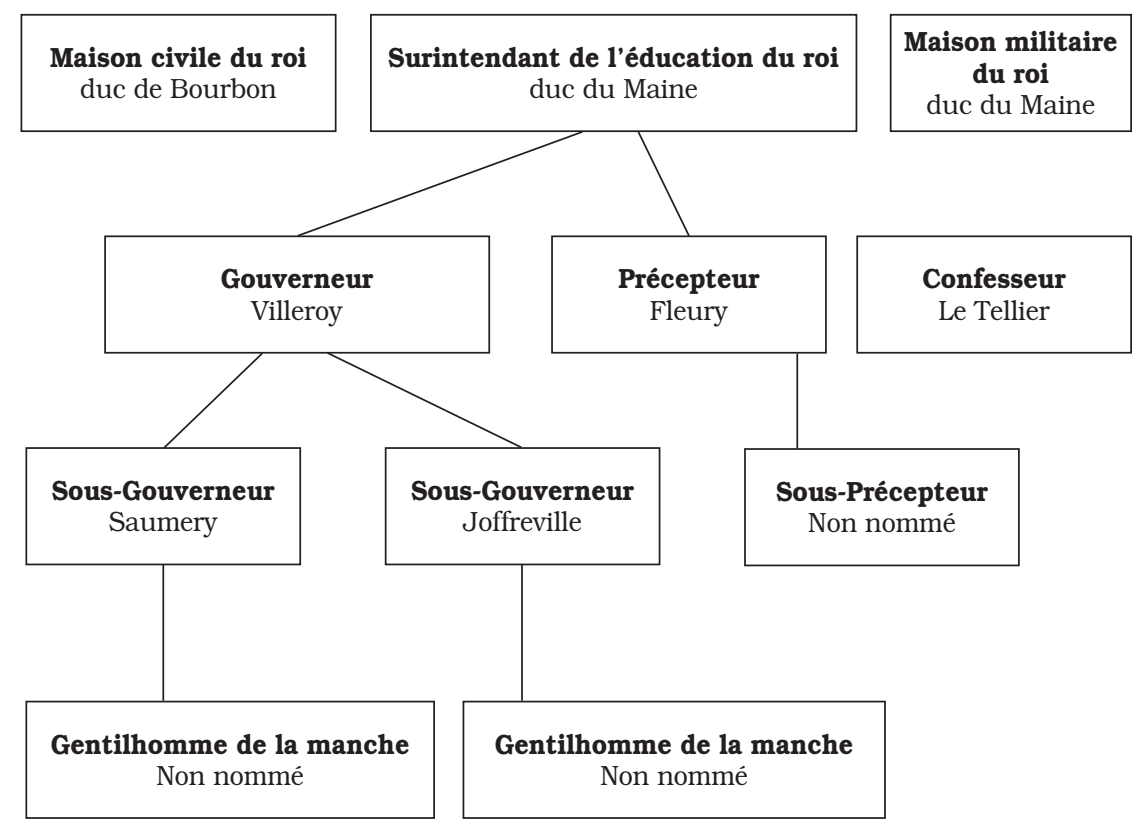

\section{2 - L'éviction du duc du Maine (1715-1718)}

Le 2 septembre 1715, au parlement, Philippe d'Orléans se fait attribuer la régence pleine et entière, c'est-à-dire la régence et la direction des troupes. Il ne peut plus se faire arrêter sur ordre du duc du Maine. Celui-ci vient de perdre la partie, il n'a plus à " répondre de la sûreté de la personne du roi et s'en tint au seul titre de surintendant de l'éducation du roi ${ }^{14}$. Le duc de Breteuil, introducteur des ambassadeurs, parle déjà " du vain titre "15.

14 Saint-Simon, éd. Cheruel, op. cit., t. VIII, p. 206.

15 Baron de Breteuil, Mémoires..., op. cit., p. 346. 
Au fil des années, la cohabitation entre le Régent, le duc du Maine et le duc de Bourbon étant toujours aussi difficile ${ }^{16}$, la décision d'évincer définitivement le duc du Maine est prise. Lors du lit de justice du 26 août 1718, trois ans plus tard, il est destitué de sa qualité de prince du sang et de sa place dans la succession royale. Villars signale que " le duc du Maine se trouvoit partout après le maréchal de Villeroy, et l'on prétendit pour cela qu'il ne pouvoit plus avoir la surintendance de l'éducation du roi $"{ }^{17}$. Maine est rétrogradé, écarté de la surintendance, quatre mois avant que n'éclate la conspiration de Cellamare ${ }^{18}$. Le gouverneur Villeroy se retrouve alors sans protecteur et " dit simplement qu'il voyoit avec douleur détruire les dispositions du feu roi "19. Les groupes écartés sont "irrigués par le Mississipi " à la hauteur de plusieurs millions de livres ${ }^{20}$.

Ce renvoi est la conséquence de trois ans de lutte politique. Le Régent a tranché. Il peut désormais se passer de ceux qui lui ont permis de consolider son pouvoir, Vieille Cour et parlement. Monsieur le duc, poussé par sa maîtresse Madame de Prie, devenu surintendant de l'éducation du roi, se désigne

16 Saint-Simon résume la situation en 1718. Le régent qui en discute souvent avec lui, ne parvient pas à éviter le conflit qu'impose en permanence le duc de Bourbon. " Par quel bout sortirez-vous donc d'ici? [...] M. le duc vous dit tout à la fois qu'il ne se soucie pas de l'éducation du roi mais qu'il la demande, et qu'on ne la peut ôter à M. du Maine que parce qu'il la demandera. Sentez-vous bien, Monsieur, toute la force de cette phrase si simple en apparence? C'est le second homme de l'État qui ne veut faire semblant que de sa haine qu'en apparence, et veut se fortifier de l'éducation sans vous montrer rien qui vous donne de l'ombrage. Après, quand il l'aura, ce sera à vous à compter avec lui, parce que vous ne lui ôterez pas l'éducation comme à M. du Maine, et comprenez ce que c'est pour un régent qu'avoir à compter avec quelqu'un [...] Pesez cette conduite avec mon goût, que je n'ai jamais caché, mais n'oubliez pas jusqu'à quel point vous vous êtes aliéné les ducs et de quelle conséquence et en même temps de quelle facilité il est de les regagner si le pied vous glisse avec M. le duc sur M. du Maine; car si vous faites la faute de lui ôtez l'éducation, tablez que lui ôter son rang avec, ne vous l'éloignera pas plus que le seul dépouillement de l'éducation, son rempart présent, et ses vastes espérances et que cela nous est si capital que vous vous en raccommoderez avec nous ". Saint-Simon, éd. Cheruel, op. cit., t. X, p. 322.

17 Claude Louis Hector, duc et maréchal de Villars, Mémoires du maréchal de Villars, écrit par lui-même, Joseph-François Michaux, Jean-Joseph-François Poujoulat (éd.), Nouvelle collection des mémoires pour servir à l'histoire de France, troisième série, tome IX, Paris, 1851, p. 249.

18 Complot ourdi en 1718 par la duchesse du Maine, et son entourage afin de faciliter l'accession au trône de France de Philippe V d'Espagne en cas de décès de Louis XV et de faire reconnaître les droits de son époux contre le régent.

19 Villars, op. cit., $3^{\text {e }}$ partie, 1718, p. 19.

20 " Il s'agit d'acheter leur silence par cette nouveauté qui est mise en œuvre au moment de la régence pour tenter de résoudre la dette héritée du règne et des guerres de Louis XIV, c'est à dire une société par action fondée sur une Compagnie maritime et coloniale du Mississipi ", Emmanuel Le Roy Ladurie, Saint Simon ou le système de la cour, Fayard, Paris, 1997, p. 456. 
grand maître de la Maison civile du jeune roi $^{21}$. Il récupère son rang et une place de choix dans la Maison du roi. Dès lors, il ne joua aucun rôle dans l'éducation.

\section{3 - La distribution des différents emplois}

Le système prévu par Louis XIV est donc caduc dès 1718. La Vieille Cour peut-elle encore longtemps résister à la Régence? Comment le Régent chargé officiellement de l'aspect politique intervient-il dans l'éducation? Pendant qu'il règle ou laisse se régler les questions d'emploi politique entre les Grands, il maintient les choix de Louis XIV en ce qui concerne les emplois d'éducation.

Les emplois d'éducation correspondent à des emplois de deux types : les emplois d'encadrement de l'enfant et ceux d'apprentissage et d'instruction. Les emplois d'encadrement sont dominés par le gouverneur. Le gouverneur sert et représente l'enfant au sens fort de la représentation monarchique. Il assure la sécurité permanente de l'enfant, jour et nuit, veille à son apprentissage de l'étiquette et de la Cour, façonne la formation de son caractère. En général, un prince royal est servi par deux sous-gouverneurs et par deux gentilshommes de la manche, emplois brigués par la noblesse. Les emplois d'éducation sont destinés à des membres moins éminents de la noblesse mais qui sont reconnus pour leur érudition et leurs qualités pédagogiques. Ces emplois sont dominés par le précepteur qui se fait aider en général par deux sous-précepteurs. Selon les apprentissages et selon les périodes, l'équipe est complétée par des maîtres qui interviennent ponctuellement, maîtres en art militaire, en mathématiques, en sciences ou en danse, dessin, escrime et musique. Les maîtres sont les représentants des métiers de Paris, des arts dont le roi se doit de connaître les rudiments pour paraître universel. Quels hommes Louis XIV avait-il choisi pour remplir ces emplois?

\section{Villeroy, le gouverneur}

Pour assurer la représentation du prince, il faut un grand seigneur habitué de la Cour, la connaissant parfaitement. Louis XIV a fait le choix de la fidélité et de la tradition. Le gouverneur choisi est François de Neufville, duc de Villeroy, maréchal de France (1644-1730) et... petit-fils du gouverneur de Louis XIV. Il semble que le choix ait été fait de longue date, lorsque l'enfant n'avait que

21 "M. le duc de Bourbon prit la parole et dit qu'il était grand maître de la Maison du roi et qu'il serait surpris si quelque autre lui en disputait le commandement ", Saint-Simon, éd. Cheruel, op. cit., t. X, p. 322 . 
quatre ans. Louis XIV avait en effet rédigé son testament le 2 août 1714, qu'il confia le 26 au premier président de Mesme et au procureur général d'Aguesseau afin qu'il soit mis sous scellés au parlement de Paris. Mais son entourage proche est au courant, comme en témoigne la lettre de $\mathrm{M}^{\mathrm{me}}$ de Ventadour. " Guand on lui [au jeune prince] a dit que M. le duc de Beauvillier étoit mort [le 31 août 1714] il a dit qui sera mon gouverneur, il faut que ce soit le gouverneur de Versailles, je crois qu'il peut lui [Villeroy] procurer des plaisirs après une pareille distinction, je crois que notre maréchal de Villeroy arrivera demain, celle que le roi vient de lui donner le met au comble de la fortune, mais celle qui le touche le plus, c'est le retour des bontés de son maître [...] je l'ai vu plusieurs fois pleurer de tendresse ${ }^{22}$. En septembre 1714, le roi nomme Villeroy ministre d'État et président du Conseil des finances.

Plusieurs raisons contribuèrent à ce choix. D'abord, l'amitié avec Louis XIV, née dans l'enfance et dans une longue vie commune. Voltaire rapporte que « Le maréchal de Villeroy, fils [sic] du gouverneur du roi, élevé avec lui, avait toujours eu sa faveur. Il avait été de toutes ses campagnes et de tous ses plaisirs : c'était un homme de figure agréable et imposante, très brave, très honnête homme, bon ami, vrai dans la société, magnifique en tout "23. Ensuite, la fidélité de la famille dans le service du roi. Les Villeroy s'étaient ralliés et avaient juré fidélité à Henri IV depuis la fin des guerres de religion, contre espèces sonnantes et trébuchantes qui ont fait leur fortune. Le ministre Villeroy, un des " barbons ", avait conseillé la reine Marie après la mort d'Henri IV en 1610. Le grand-père, Nicolas de Neufville, premier duc de Villeroy, était gouverneur de Louis-Dieudonné en mai 1646. C'est donc une tradition familiale qui l'emporte comme souvent à Versailles. Le grand-père fut gouverneur du grand-père, le petit-fils sera gouverneur de l'arrière-petit-fils.

Une autre particularité de cette transmission voulue par Louis XIV se trouve dans l'absence de délai. "Le maréchal de Villeroy aura le titre de gouverneur suivant ce qui est porté par mon testament, aura l'œil sur la conduite du roi quoiqu'il n'ait pas encore sept ans, jusqu'auquel âge de sept ans accomplis, la duchesse de Ventadour demeurera ainsi qu'il est accoutumé, gouvernante et

22 Bibliothèque municipale de Versailles, M56, Manuscrit n ${ }^{\circ} 24$, fol. 31, lettre de Madame de Ventadour à Madame de Maintenon, du 9 septembre 1714, publiée dans L.A. de La Baumelle (éd.), Lettres de $M^{\text {me }}$ de Maintenon, t. VII, 1758, p. 22.

23 Voltaire ajoute en note "l'auteur, qui dans sa jeunesse eut l'honneur de le voir souvent a droit d'assurer que c'était là son caractère ". Voltaire, Le siècle de Louis XIV, in René Pomeau (éd.), Voltaire, CEuvres historiques, Paris, Gallimard, 1957, 1814 p., p. 815. 
chargée des mêmes soins qu'elle a pris jusqu'à présent " ${ }^{24}$. Le roi maintient de façon exceptionnelle, ensemble et pendant deux ans, l'emploi de gouvernante et de gouverneur. C'est un cadeau qu'il fait à son vieil ami Villeroy et à l'amie de Madame de Maintenon, Madame de Ventadour. Nul n'ignore à la Cour les relations acceptées par tous, de Villeroy avec la gouvernante ${ }^{25}$.

Le jeune roi passa donc progressivement des mains de la gouvernante à celles du gouverneur. Ces précautions sont prises afin qu'il ne soit pas troublé par le changement de personnel. L'enfant voit donc son futur gouverneur très fréquemment avec Madame de Ventadour dans le cercle des intimes de Madame de Maintenon. Cette continuité est un fait assez rare qu'il convient de mentionner, dont le premier exemple fut celui du grand dauphin passant successivement des mains de Julie d'Angennes à celle de son mari, le duc de Montausier. Et non simultanément.

En choisissant Villeroy, Louis XIV choisit un courant politique. Il entend que soit conservée après sa mort, la mémoire des premières formes de l'absolutisme et de la représentation royale dont Villeroy, qui l'accompagne depuis les années 1650, serait le garant. Avec ce choix au premier plan d'un membre éminent de la Vieille Cour, est conservé près du roi un partisan de l'Espagne. En dernier lieu, avec cette famille fidèle au courant catholique traditionnel, respectueuse de Rome et proche de jésuites, le roi donne un gage de modération et un interlocuteur à l'Église, dans le contexte de la bulle Unigenitus non encore approuvée par l'ensemble du clergé français ${ }^{26}$. Louis XIV connaît les capacités de Villeroy qu'il sait pouvoir équilibrer par d'autres hommes.

\section{Fleury et le réseau de Madame de Maintenon}

Les hommes choisis pour aider le gouverneur sont issus du réseau de Madame de Maintenon. Celle-ci s'est fait une spécialité des emplois d'éducation. Après avoir elle-même fait fortune en élevant le duc du Maine et son

24 Baron de Breteuil, Mémoires..., op. cit., p. 340-342.

25 "Il y avoit plus de cinquante ans que le maréchal de Villeroy et elle se faisoient fort publiquement l'amour, sans toutefois s'en contraindre de part et d'autre pour ce qu'ils trouvoient à leur gré et sans que cette liberté réciproque altérât le moins du monde leur commerce, sur lequel la plus intime amitié et confiance s'étoit entée ". Saint-Simon, ibid., p. 373.

26 L'insistance de Saint-Simon fonde beaucoup de jugements sur Villeroy : "Tout ce qui fut nommé par anticipation pour l'éducation du roi futur n'eut d'autres motifs que l'intérêt des bâtards. M. le duc du Maine fut mis à la tête et sous lui, le maréchal de Villeroy, l'homme le plus inepte à cet emploi qu'il y eut peut-être dans toute la France ". Saint-Simon, éd. Cheruel, op. cit., t. VIII, p. 174. S'en tenir à cette critique rend incompréhensible le choix du roi. 
frère Toulouse, après avoir suivi de très près le groupe d'éducation du duc de Bourgogne, le petit-fils de Louis XIV qui fut dauphin entre 1711 et sa mort en 1712, après avoir supervisé l'éducation des demoiselles de Saint-Cyr, n'envisageait-elle pas à nouveau de s'ingérer dans l'éducation du jeune Louis XV? Malgré la mort de Louis XIV, à qui elle doit son pouvoir, puis le passage de Louis XV aux hommes, le lien n'est pas rompu entre Madame de Maintenon et Madame de Ventadour, bien qu'après 1717 celle-ci ne doive plus approcher sans autorisation de celui qu'elle a élevé. Madame de Maintenon, retirée à Saint-Cyr, conserve ainsi des contacts épistolaires avec ses amis dont le sujet principal est le jeune Louis et qui témoignent de son intérêt pour la question.

Pendant toute la période, Madame de Maintenon soutient à la Cour François de Villeroy ${ }^{27}$. En 1714, elle avait fait nommer instituteur du jeune Louis Robert Perrot, l'archidiacre de son propre confesseur, Godet des Marais. Sa grande réussite est la nomination de l'évêque de Fréjus, André-Hercule de Fleury comme précepteur en 1715. Madame de Maintenon l'a tiré de son évêché de Fréjus, sans doute sur le conseil des Noailles ${ }^{28}$.

Sa nomination prouve l'art de l'intrigue de Fleury, autant que la flexibilité de son caractère et sa capacité d'adaptation. Arrivé à Paris vers 1666 à l'âge de treize ans, Fleury accompagne à la Cour le cardinal de Bonzi, évêque de Montpellier, auquel son père l'a confiée ${ }^{29}$. Il apprend les manières de Cour de cet élégant aumônier de la reine. De 1678 aux années 1690, il assiste Louis XIV comme aumônier du roi à la chapelle et dans les cérémonies de Cour. Il mise ensuite sur l'ascension du cardinal de Bouillon, grand aumônier du roi, mais doit faire oublier ce choix devenu maladroit après la disgrâce de celui-ci en 1685. Bien qu'il soit parvenu à cet emploi d'aumônier du roi grâce à Bonzi, Fleury lui préfère l'homme auquel Bonzi s'oppose à la fin de sa vie : l'intendant du Languedoc, Lamoignon de Basville. Fleury suit le choix du roi qui, en 1685,

27 " Nous en étions donc là, ensemble lorsque aussitôt après la mort de Monsieur [le duc de Bourgogne] et de $\mathrm{M}^{\mathrm{me}}$ la Dauphine, $\mathrm{M}^{\mathrm{me}}$ de Maintenon le [Villeroy] tira de la plus profonde disgrâce, et le fit subitement paroitre à Marly en favori ". Saint-Simon, éd. Cheruel, op. cit., t. VII, p. 368.

$\mathrm{M}^{\mathrm{me}}$ de Caylus écrit le 16 novembre 1715 à sa tante retirée à Saint Cyr : " Je vous envoie une lettre de M. de Fréjus. Il vient me voir de temps en temps, il me semble qu'il est des nôtres ». Pierre-E. Leroy et Marcel Loyau (éd.), Dans L'estime et la tendresse. $M^{\text {me }}$ de Maintenon, $M^{\text {me }}$ de Caylus et $M^{\text {me }}$ de Dangeau ; correspondances intimes, Paris, Albin Michel, 1998, p. 309. Ces lettres de Madame de Maintenon à Madame de Caylus et Madame de Dangeau permettent de préciser des aspects de cette période de Fleury, car celui-ci n’a pas laissé de papiers personnels.

Voir à ce sujet l'article de Peter Campbell dans le présent numéro. 
vient de confier à Basville les persécutions des protestants en Languedoc. Sans famille puissante, il lui faut être habile, brillant mais servile.

Fleury " était fort beau et fort bien fait [...], sa figure adoucit les esprits [...] mais le roi n'avait pas tort de n'y trouver rien d'ecclésiastique et que quoiqu'il se conduisît fort discrètement, il étoit difficile que tout en fût ignoré " ${ }^{30}$. Le roi accepte d'oublier quelques aventures mais il lui fait attendre longtemps un évêché. Ce fut celui de Fréjus, en remplacement du frère du médecin du roi, d'Aquin. Dans une lettre à Noailles du 2 novembre 1699, Madame de Maintenon s'en félicite : " Je suis bien contente de la promotion, parce qu'il me semble que vous l'approuverez, et qu'elle marque la considération que le roi a pour vous, et l'abbé de Fleury n'était pas, par lui seul, personne à être sitôt évêque ${ }^{31}$. C'est donc par le réseau Noailles que Fleury obtint son évêché.

Habile encore, le languedocien Fleury comprenant l'importance stratégique de cet évêché de Fréjus. Il rend des services lors de la guerre de succession d'Espagne sur lesquels beaucoup d'historiens aimeraient avoir des détails. Il protège son diocèse des violences du passage des troupes d'Eugène et de VictorAmédée de Savoie, dont il se fait apprécier, tout comme du duc de Toscane. Les Provençaux lui en sauront gré. Comment savoir s’il participe au réseau d'informateurs dans le sud de la France et le nord de l'Italie, que son ami l'abbé de Pomponne, ambassadeur à Venise, organise à partir de 1705 pour le compte du ministre de la guerre (Chamillart), alors que Pomponne est au service du ministre des Affaires étrangères (Torcy)? Il est probable que Fleury avait tissé des liens avec ceux-ci pendant leur voyage commun à Rome aux côtés du cardinal de Bonzi. Il avait alors été présenté à l'ambassadeur à Rome, le cardinal Forbin-Janson ${ }^{32}$, avant de l'être auprès du grand duc de Toscane puis de visiter la république de Venise.

Fleury s'est fait apprécier des familles provençales, des parlementaires d'Aix, les Forbin, Vintimille, Simiane et Valbelle. Si les sources restent silencieuses sur cette période, pendant la quinzaine d'années passées à Fréjus, Fleury

30 Saint-Simon, éd. Cheruel, op. cit., t. I, p. 585.

31 Henri Druon, L'éducation des princes dans la maison des Bourbons de France, t. II, Paris : P. Lethielleux, 1897, p. 203. Il est ami de $\mathrm{M}^{\mathrm{me}}$ de Dangeau.

32 Toussaint de Forbin Janson (1629-1713) fut évêque de Digne puis de Marseille. Il devient cardinal en 1689. Le roi qui a repéré son talent de négociateur, l'envoie comme ambassadeur en Pologne puis à Rome pour différents conclaves. De 1693 à 1700, il est chargé des affaires de la France à Rome, puis Grand aumônier de France en 1706. Il mène alors grande vie à Versailles, entouré de l'archevêque de Marseille puis d'Aix, $\mathrm{M}^{\mathrm{gr}} \mathrm{du}$ Luc et de son frère, l'ambassadeur en Suisse. Tous ces Provençaux sont amis de Fleury. 
conserva ses liens avec Versailles et notamment à la Cour, avec le réseau des Provençaux et celui des Languedociens, justement organisé autour du duc du Maine et des Noailles ${ }^{33}$.

Dès 1711, alors que conflit entre les partisans de Jansen et le roi n'est toujours pas réglé et menace de s'envenimer, Fleury œuvre au service des positions royales. C'est un engagement que Louis XIV apprécie. En effet, il avait déjà fait connaître sa fidélité doctrinale à la position monarchique dans l'assemblée du clergé de 1682, en s'activant pour soutenir le roi face au pape Innocent XI (1676-1689), alors certains s'opposaient à lui sur le problème de la régale. En 1713, alors que le cardinal de Noailles hésite à accepter la bulle Unigenitus, il cède à l'influence de Fleury et se soumet au roi. Fleury le félicite le 17 octobre $1713^{34}$. Fleury, très lié aux Noailles, utilise une fois de plus son talent de persuasion et prouve qu'il peut faire fléchir son protecteur.

Madame de Maintenon parvint à le faire nommer précepteur par le deuxième codicille, consacré exclusivement à l'accompagnement éducatif et moral du futur roi. "Louis, par la grâce de Dieu Roi de France [...]. Je nomme Précepteur du Dauphin le sieur de Fleury, ancien Évêque de Fréjus, et pour Confesseur le Père Le Tellier, ce $23^{\mathrm{e}}$ août 1715 . Signé Louis ${ }^{35}$. Il est nommé dans une période particulière, cette période de vacance des nominations décidée par Louis XIV au début du mois d'août 1715 en raison de sa maladie. Le second codicille est signé, le jour même où il reçoit l'extrême onction. Sa dernière intention est celle de donner un précepteur au futur roi, geste ultime d'attachement à l'éducation de celui-ci.

Habitué de la Cour, apprécié par la Vieille Cour, soutenu par Madame de Maintenon qui cherche à placer des hommes favorables aux intérêts du duc du Maine, son ancien élève, Fleury recueille les fruits de sa patience et de son habilité. Gallican modéré, il rassure le Saint-Siège. Le choix du roi se caractérise donc bien par une volonté de continuité et de pacification religieuse au travers de la personne de Fleury précepteur. Et, raison supplémentaire de

33 Le duc du Maine dès l'âge de douze ans, est gouverneur du Languedoc. Ces fonctions sont confiées, depuis 1682, au duc puis maréchal Anne-Jules de Noailles (né en 1650), frère du cardinal Louis-Antoine de Noailles (né en 1651). Le duc d'Ayen puis de Noailles, époux de la nièce de Madame de Maintenon, reçut des signes d'éminente faveur de Louis XIV qui lui confia ses papiers personnels en 1714. En 1715, il a trente-sept ans et ses deux fils sont compagnons d'enfance de Louis XV.

35 Le dernier codicille est daté du 23 mais le roi le signa le 25 août dans ses derniers moments, puisqu'il reçoit l'extrême-onction le jour de la Saint Louis. 
ce choix, André Hercule Fleury (62 ans) a assisté, en témoin passif certes, aux éducations précédentes.

Au premier Conseil de régence, Fleury est confirmé par le Régent qui maintient en cela le choix de Louis XIV qui " le nomma pour cet important emploi par son dernier codicille écrit de sa main quelques jours avant sa mort, par la connaissance qu'il avait de sa vertu, de son érudition, de son attachement à notre service et nous [le Régent] sommes portés d'autant plus volontiers à confirmer ce choix que nous avons reconnu ledit évêque de Fréjus pour bien remplir sa place et que les témoignages qui nous ont été rendus, lui ont été à son avantage " ${ }^{36}$. Villeroy a-t-il soutenu Fleury auprès du Régent? Ou le Régent connaissait-il Fleury depuis la guerre d'Espagne? Beaucoup de questions restent posées, sans qu'il soit possible d'y répondre en l'état actuel de la documentation. Pour parvenir à cette consécration, Fleury a su faire évoluer ses relations en opérant des changements opportuns de réseaux. Il s'est donc révélé adroit politiquement, ce qui est une qualité à enseigner au jeune roi.

\section{Les emplois de second rang}

Louis XIV ne prévoyait pas de sous-précepteur. Le Régent trouve cependant nécessaire d'en nommer un. Il se fie au choix fait pour Bourgogne et Anjou après 1698 : il nomme l'abbé Vittement, ancien recteur de la Sorbonne ${ }^{37}$.

Le personnel de service est lié au duc de Bourgogne. Louis XIV pressent l'isolement du dauphin orphelin. Il connaît la nécessité de la transmission entre père et fils. Elle a été rompue par la mort. Il prévoit en conséquence deux sous-gouverneurs qui ont bien connu Bourgogne, Saumery et Joffreville. Les Saumery, liés à Beauvillier depuis l'éducation de Bourgogne et de ses frères dont il était gouverneur, sont présents à la Cour ${ }^{38}$. En fait, d'autres sousgouverneurs suppléeront ceux réellement prévus. Joffreville le Danois refuse l'emploi de sous-gouverneur de Louis XV, car il sait que le Régent lui réserve une place au Conseil de guerre ${ }^{39}$. Il est remplacé par le comte de Ruffey, aide de camp du duc de Bourgogne dans la guerre des Flandres en 1708, chargé de

36 BnF, Naf 22405, fol. 11.

37 Vittement est choisi pour avoir ébloui la cour en parlant " d'une justesse et à l'éloquence mâle et naturelle " plus convaincante que l'orateur favori de cette période, le cardinal de Polignac.

38 Respectivement gouverneur et sous-gouverneur, ainsi que beaux-frères.

39 Le marquis de Joffreville devint lieutenant général en octobre 1704. Le duc de Bourgogne le recommande alors à son frère. Il combat en Espagne, où il passe dans la clientèle du duc d'Orléans et puis au Portugal. Il est désigné le 3 juin 1714 comme l'un des quatre lieutenants généraux qui devaient accompagner Berwick en Espagne. 
négociation à la conférence de Tourcoing. Le duc du Maine peut compter sur la fidélité de Ruffey. On souligne assez peu les fidélités nées des combats de Bourgogne adulte, en Espagne, fidélités brisées par la mort et restées jusque-là sans avenir. Ces militaires obtiennent ces postes en son souvenir.

Les autres emplois de service sont âprement négociés. Le marquis Louis de Prie, pour lors ambassadeur à Turin, devient sous-gouverneur du fait de son titre de parrain. En effet, sa cousine, la gouvernante des princes, Madame de Ventadour, constatant la série de décès rapides, avait préféré assurer la protection de l'âme des jeunes princes et les avait fait baptiser en mars 1712 . Dans cette période d'affolement dans la famille royale, elle avait choisi ellemême, parrain et marraine parmi les membres de sa propre famille ${ }^{40}$. Avec esprit d'à-propos, la gouvernante ne laissa échapper aucun poste, investissement pour la bonne cause et dont personne ne lui tiendra rigueur, mais à moitié rentable en raison de la mort de Bretagne le 8 mars 1712. Cependant, contrairement à Mazarin, parrain de Louis XIV, le parrain du futur Louis XV n'est pas digne de devenir surintendant de son éducation. Son poste d'ambassadeur auprès du duc de Savoie à Turin aurait pu lui être favorable. L'autre grand-père, le duc de Savoie, dont les historiens français tiennent peu compte dans ces nominations, a tissé des liens directs avec les hommes nommés auprès de son petit-fils (Prie, A. H. de Fleury).

Comme pour de nombreux emplois à ce niveau, les réseaux fonctionnent à plein. La nomination des gentilshommes de la manche est négociée par Madame la duchesse de Berry avec son père, le Régent. Elle vient de changer d'amant et "Les nouveaux goûts de cette princesse lui firent chercher à récompenser ses anciens pour s'en défaire honnêtement. [...] À cette occasion, Madame la duchesse de Berry voulut que La Haye, qui avait perdu la charge qu'elle lui avait fait donner chez M. le duc de Berry, eût une place de gentilhomme de la manche, qui vaut six mille francs par an. Le roi en avait deux, et il n'y en avait jamais eu davantage. Ce troisième fit donc difficulté. Pour la lever, on souffla

40 Le duc de Bretagne, futur dauphin par l'éminence de la mort de son père le duc de Bourgogne, eut comme marraine Madame de Ventadour, et comme parrain le cousin de celle-ci, le comte de la Mothe. Le duc d'Anjou, futur Louis XV eut comme parrain l'autre cousin de celle-ci, le marquis de Prie, et comme marraine la propre sœur de la gouvernante, la duchesse de la Ferté. Breteuil écrit avec désespoir : "Hélas! Le jour de cette dernière audience [de l'envoyé de Lorraine] fut encore un jour terrible pour la France. Le petit dauphin et le duc d'Anjou, à l'extrémité l'un et l'autre de cette maudite rougeole qui nous a causé tant de malheurs, furent baptisés précipitamment l'après-dîner par l'évêque de Metz, premier aumônier du roi. Et le dauphin, déjà grand et fort, autant qu'un enfant de cinq ans peut l'être, mourut. Il nous laissa pour toute espérance son frère mourant et âgé de deux ans ". Baron de Breteuil, Mémoires..., op. cit.,, 1992, p. 313. 
à la duchesse de Ventadour d'en demander un quatrième, moyennant quoi La Haye passa " ${ }^{41}$. Tandis que la duchesse de Berry place son ancien amant, Louis Berault, marquis de La Haye, Madame de Ventadour en profite pour faire nommer le jeune marquis d'Aussy et le chevalier Hubert de Courtavel, marquis de Pezé, son cousin. Le Régent place enfin comme quatrième gentilhomme de la manche le jeune Michel-Jean de Gouy, marquis d'Arcy, un parent de René d'Arcy, son propre gouverneur. Finalement de deux gentilshommes de la manche prévus, "le roi en eut quatre " ${ }^{42}$. Le Régent sait que par les emplois de service qui ont accès en permanence au prince, l'influence peut être forte. De plus, c'est par eux que chacun compte être informé des faits et gestes de l'entourage du roi. La structure du personnel est donc finalement complète en 1717.

L'équipe reflète une gradation des âges en fonction des fidélités. Louis XIV a nommé des septuagénaires (Villeroy : 73 ans, A-H. Fleury : 64 ans). Madame de Maintenon a favorisé des hommes de l'âge du duc du Maine, des quinquagénaires. Les trentenaires qui ont l'âge du duc de Bourgogne, sont sousgouverneurs ou gentilshommes de la manche, eux qui dans l'équipe sont les plus affairés pour accompagner le jeune roi dans ses activités diverses. En 1715 le duc du Maine (47 ans alors) avait un âge respectable pour détenir la surintendance, tandis qu'en 1717 le duc de Bourbon fait par contraste figure de jeune arriviste (25 ans).

\section{Le confesseur du roi}

L'emploi de confesseur du roi représente un autre enjeu de pouvoir immédiat, qui se pose dès la mort de Louis XIV. En effet, le confesseur du roi tient alors " la Feuille ", c'est-à-dire la nomination aux plus hautes charges ecclésiastiques du Royaume. Le milieu des ecclésiastiques est alors perturbé par la complexe question religieuse de la bulle Unigenitus et de la controverse entre gallicans et partisans des jésuites, non résolue sous Louis XIV. En août 1715, Louis XIV avait maintenu dans son dernier codicille le père Le Tellier, jésuite, comme confesseur de son successeur, alors que s'agitaient des conseillers du prince cherchant à éloigner la Compagnie de cet emploi ${ }^{43}$. Le Régent différa la

41 Saint-Simon, Mémoires, Yves Coirault (éd.), Gallimard (coll. Pleiade), 7 vol., 1983-2000, vol. V, p. 877.

42 idem.

43 Le cardinal de Noailles conclut un mémoire au régent en disant " qu'on ne devoit point donner au roi comme confesseur un homme de communauté et encore moins un jésuite ". Antoine d'Orsanne, Journal de M. l'abbé Dorsanne, Rome [Amsterdam], 1753, septembre 1715, t. II, p. 13. 
question en prétendant que le jeune roi n'aurait de confesseur que pour ses sept ans. Il rencontra le père Le Tellier le 28 octobre 1715, qui reçut le conseil de partir pour Amiens, ce qu'il fit sans éclat à la fin novembre 1715. On a l'impression que l'affaire est momentanément réglée, mais elle rejaillit un an plus tard.

En effet, la Vieille Cour reste active. En novembre 1716, un jésuite, le père de la Ferté, cousin par alliance de la gouvernante Madame de Ventadour, est désigné par le cardinal de Rohan, grand aumônier, pour prêcher l'Avent au roi, contre l'avis du cardinal de Noailles et du Régent. Afin d'éviter d'attiser le conflit religieux dans cette période où le Régent cherche des accommodements, le père la Ferté reçoit le conseil de se retirer et de laisser prêcher l'abbé Couturier, de Saint-Sulpice, ami de A. H. de Fleury.

Le Régent décide alors de ne plus surseoir au choix de cet emploi de confesseur. Il nomme fin novembre 1716, le vieil abbé Claude Fleury, spécialiste des éducations princières depuis celles du grand dauphin et des princes de Conti en 1670. Claude Fleury passe ainsi de l'emploi de conseiller de Fénelon, de sous-précepteur du duc de Bourgogne, à celui de confesseur de son fils. Il passe d'un emploi d'éducation à un emploi de conseiller spirituel, beaucoup plus tranquille vu son grand âge et qui correspond à la reconnaissance royale d'une carrière totalement dévouée à l'éducation des princes. Il est choisi comme un élément de pacification puisqu'il n'appartient alors à aucun clan. Les jésuites ne réagissent pas, attendant un événement important pour relancer l'offensive : la communion du roi en 1722. Comme on le voit, ce sont donc surtout des considérations politiques et religieuses qui ont conditionné pendant ces années le choix des hommes qui entourent le jeune roi.

Pour conclure sur cette partie descriptive, on ne peut que constater que pendant ces trois ans, de 1715 à 1718, le Régent est intervenu le moins possible dans les équilibres politiques entre haute noblesse et princes de sang. Pour respecter les équilibres dont il avait besoin pour gouverner momentanément, il a pris appui sur la Vieille Cour, en les personnes de la gouvernante et du gouverneur, tout en plaçant ses clients. Le Régent a maintenu une partie du personnel d'éducation prévu par Louis XIV. Somme toute, il a fait le choix de conserver la tradition éducative : sur les onze personnes nommées, sept ont déjà servi dans l'éducation des princes précédents. 
Tableau 3 : Le dispositif réaménagé par le Régent (1715-1722)

(1715-1718) : dates d'exercice de la fonction

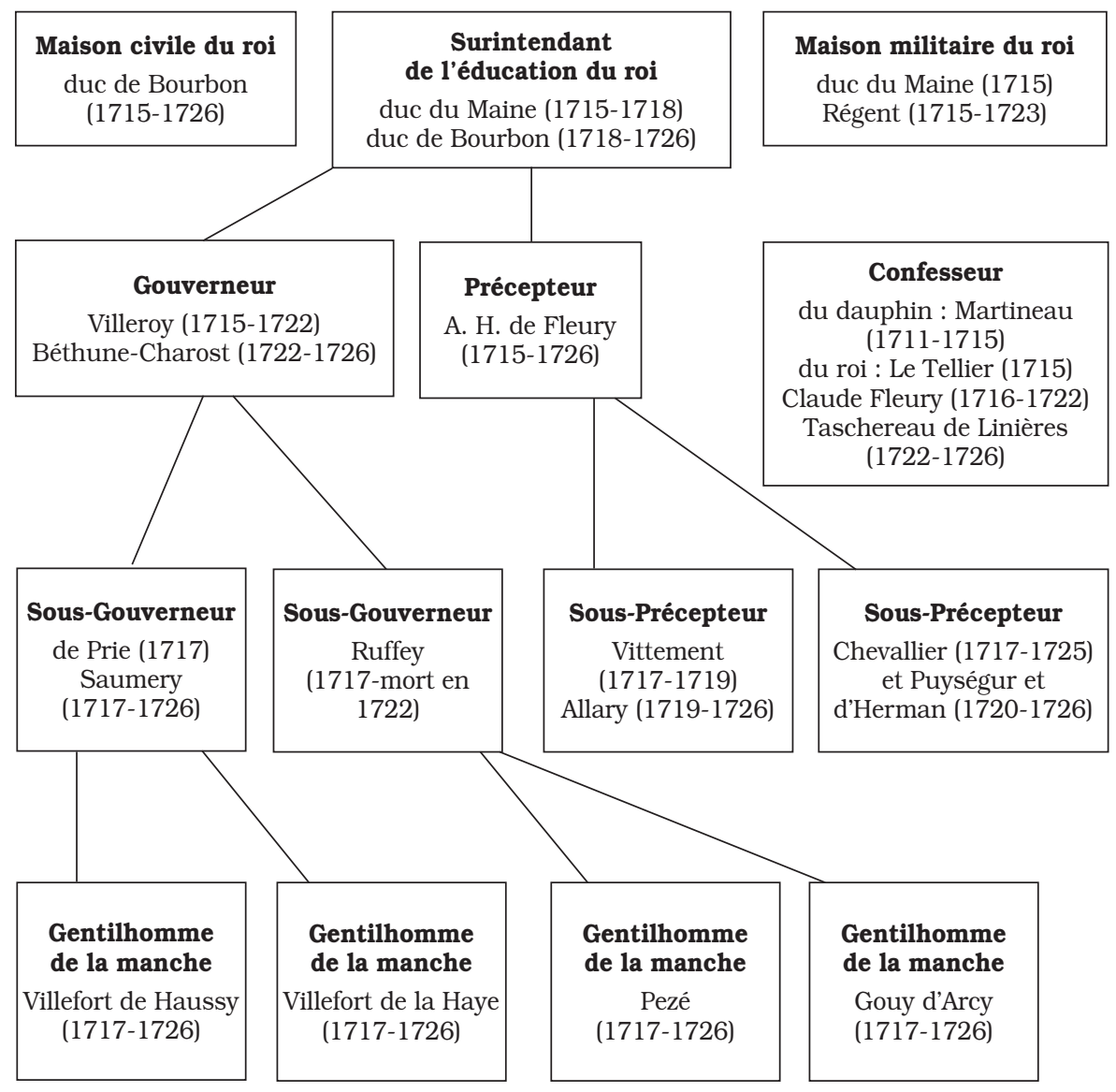

\section{II - L'équipe éducative au travail (1719-1723)}

Quelle éducation faut-il pour former un roi? Examinons maintenant cette équipe en fonctionnement dans les années 1719-1723. Dans quelle mesure, les hommes de la Vieille Cour peuvent-ils peser dans l'éducation du roi face à un Régent qui décide progressivement d'intervenir dans l'éducation proprement dite? 


\section{1 - Villeroy et l'apprentissage d'une civilité royale}

Deux hommes représentants de la Vieille Cour sont quotidiennement en charge de l'éducation. Après que la conspiration de Cellamare a été tranchée par le Régent, Villeroy a bien des raisons de trembler. En effet, contrairement aux autres équipes éducatives, le gouverneur n'a pas nommé d'homme à lui. Villeroy est ainsi isolé après 1718 et doit compter sur le soutien de Fleury. C'est peut-être la raison pour laquelle il impose au jeune roi une discipline de fer, afin qu'on ne lui reproche rien. En 1719, l'éducation de Louis XV est donc encore conforme aux attentes de la Vieille Cour : éducation religieuse et histoire morale y prédominent.

Villeroy ne néglige rien pour faire acquérir au roi un comportement majestueux, digne de son ancêtre. Louis XIV avait un comportement royal, et bien, Louis XV acquiert ces attitudes avant l'âge de sept ans. On le remarque nettement lorsqu'il assiste aux différents lits de justice. Il est majestueux et hautain comme Villeroy lui a déjà appris à l'être quand il faut se composer une figure ${ }^{44}$. Prévenu, il s'efforce de ne pas réagir lors du renvoi de son grand-oncle. En privé, cette contrainte le rend malade comme en témoigne souvent Madame de Ventadour ${ }^{45}$. Villeroy exige du jeune roi une attitude d'adulte. Les représentations monarchiques sont lourdes, calquées sur les capacités extraordinaires de Louis XIV. Or Louis XV est un enfant émotif qui n’apprécie pas de manger au grand couvert et déteste être exhibé face à la foule. Pourtant il sort dans Paris au moins une fois par semaine ${ }^{46}$. Louis XIV dansait. Le jeune roi danse en public aux carnavals de 1719 à 1721 . Puis le renvoi de Villeroy et la mort du gentilhomme de la chambre, le duc d'Aumont, chargé de la mise en œuvre des

44 "J'avois observé le roi lorsqu'il fut question de son éducation, je ne remarquai en lui aucune altération, de changement, pas même de contrainte. C'avoit été le dernier acte du spectacle, il en étoit tout frais lorsque les enregistrements s'écrivirent. Cependant, comme il n'y avoit plus de discours qui occupassent, il se mit à rire avec ceux qui se trouvèrent à portée de lui, à s'amuser de tout [...]. Cette indifférence pour M. du Maine frappa tout le monde et démentit publiquement ce que ses partisans essayèrent de répandre que les yeux lui avoient rougi, mais que ni au lit de justice, ni depuis, il n'en avoit osé témoigner. Il ne prononça le nom du duc du Maine qu'une seule fois, qui fut l'après-dîner du même jour, qu'il demanda où il alloit d'un air très indifférent, sans en dire davantage, ni depuis, ni nommer ses enfants. "Saint-Simon, Mémoires, éd. Cheruel, op. cit., t. X, p. 405 .

45 "Souvent il n'auroit pas mangé quand il estoit dauphin s'il n'etoit venu chez moi mais ces règles en spectacles me désolent souvent j'y remédie incognito autant que je le peux ". Lettre de Madame de Ventadour à Madame de Maintenon à Versailles, 24 février 1716 (Bibliothèque municipale de Versailles, M 56, Manuscrit n ${ }^{\circ}$ 6, fol. 78).

46 Le 19 juin 1716, " Hier nous vîmes le roi dans les Tuileries en allant au salut chez les Feuillants. S. M. étoit dans une chaise roulante poussé par huit suisses, mangeant un biscuit et paraissant bien se porter ". Jean Buvat, Barthélémy Edouard, Gazette de la régence, Paris, G. Charpentier, 1887 , p. 89. 
ballets royaux et enfin une nouvelle maladie du roi mirent un terme en 1721 à ce type de représentation dansée de la monarchie.

Villeroy exige du jeune roi une pratique religieuse irréprochable, cette pratique constituant bientôt un enjeu dans la querelle politico-religieuse. Le dimanche de Pâques, le 28 mars 1717, le roi se confesse pour la première fois. Un débat éclate sur sa présence chez les jésuites, à la maison professe de la rue Saint-Antoine, le $1^{\mathrm{er}}$ janvier 1718. Il faut faire appel à une justification historique : "le feu roi, quand il était à Paris, allait tous les premiers jours de l'an entendre le salut aux Jésuites et c'est sur cet exemple-là qu'on y a amené le roi $"{ }^{47}$. Buvat se fait aussi le témoin de ces propos, qu'il a entendu dans la rue, signe que le public a été volontairement informé et pris à témoin.

Pour compenser cette faveur faite aux jésuites, pendant les dix dimanches de Carême de 1718, le roi entend les Sermons de Massillon. Ce célèbre prélat est soutenu par Dubois qui espère devenir cardinal. Le "Petit Carême " est recopié, car on prétend que le roi voulut en posséder le texte ${ }^{48}$. Ainsi continue la guerre des " communiqués de presse ".

\section{2 - L'évolution des enseignements dispensés au roi (1715-1722)}

De son côté, Fleury occupe depuis deux ans les fonctions de précepteur. Il propose une éducation fondée sur l'apprentissage des textes sacrés, sur l'histoire des ancêtres du roi, à travers un immense Abrégé d'histoire de France en cinq tomes, des exercices de latin reposant sur les vertus du plus chrétien des ancêtres, saint Louis ${ }^{49}$. Fleury assure l'instruction religieuse quotidienne du roi, lui imprime un placard donnant les commandements de Dieu et ceux de l'Église, puis un autre sur des Préceptes de sagesse. Le roi apprend également son rôle de chef de l'Église, en recevant fin mai 1718 les serments de la quinzaine de postulants en attente d'un évêché dont la situation est bloquée entre le pape et le Régent. Il apprend à connaître l'espace religieux de la capitale en allant en juin 1718 faire ses dévotions tous les jours de la Fête-Dieu dans une église différente de Paris. L'année 1718 est particulièrement consacrée à

47 Pierre-Édouard Lémontey, Philippe de Courcillon Dangeau, Essai sur l'établissement monarchique de Louis XIV [...] Précédé de nouveaux mémoires de Dangeau, Paris, Deterville, 1818, p. 285.

48 Introduction du Carême de Massillon. BnF, mss 9650.

$49 \mathrm{BnF}$, mss fr 2324, Versions du roy Louis XV écrittes de sa main extraittes des plus beaux endroits de la vie de Saint Louis (1717-1720). Voir à ce propos Chantal Grell, L'Abrégé de histoire de France écrit pour le jeune Louis XV, Montigny-le-Bretonneux, Archives départementales des Yvelines, 2004 et son article dans le présent numéro. 
l'apprentissage des rites, du culte et de l'éducation religieuse. Mais, à chaque sortie, il y a des conflits de préséance entre le surintendant et le gouverneur. Heureusement, le roi est souvent souffrant, prétexte tout trouvé pour échapper à ces interminables querelles comme en témoigne régulièrement la Gazette. L'éducation du roi très-chrétien fut menée sans aucune faille, de façon à reproduire les pratiques religieuses du règne précédent.

Le Régent introduit pourtant des nouveautés. Il est toujours intervenu à la marge, afin d'écarter les bornes fixées par la Vieille Cour. Il est responsable de l'intérêt que Louis XV porte à la géographie, ce qui n'est pas traditionnel dans une éducation royale. Il a encouragé sa formation dans cette matière en faisant intervenir Guillaume Delisle, le fils de son ancien maître de géographie. Le Régent lui fait visiter les cabinets scientifiques de ses amis. Par exemple, le 25 juillet 1717, la Gazette est chargée d'informer la population qu'ils sont allés au château de Bercy visiter le cabinet scientifique de M. Pajot d'Ons en Bray. Le roi fut tellement passionné que la Gazette signale qu'il est rentré vers les huit heures du soir.

Voilà un enfant d'une dizaine d'années, solitaire et timide, qui fait preuve en public (devant le nonce, devant le tsar, devant le maréchal de Villars) de connaissances de religion, d'histoire, de généalogie, de géographie et qui manifeste la maîtrise des comportements royaux lorsqu'il est en représentation. Tout ceci reflète une éducation princière classique. Le jeune roi a désormais dix ans. Les bases de l'éducation lui ont été données. Il reste à en faire un roi.

À partir de 1719, plusieurs indices montrent que les choses changent : le Régent impose le roi comme le protecteur de toutes les académies royales, que l'enfant visite à marche forcée entre le 21 juillet et le 15 août 1719. Puis Philippe d'Orléans cherche à soustraire le jeune roi à l'influence de son gouverneur. Le premier endroit calme trouvé fut le cabinet d'étude. Le gouverneur n'y est pas présent, puisque l'enfant y est confié à son seul précepteur. Le Régent fait donc aménager pour Louis XV un petit pavillon de deux pièces, au bout de la terrasse du bord de l'eau au jardin des Tuileries. Ce pavillon meublé est entouré d'un jardinet où le roi dispose d'outils en argent, d'une volière nichée dans les arbres et même d'une petite vache blanche qu'il avait eue à Bagatelle. De Vincennes qu'il occupait en 1715, l'ayant installé aux Tuileries, le Régent éloigne toujours plus le roi vers l'ouest de la capitale, l'invite au château de la Muette, qu'il finit par lui vendre à l'été 1719 . Tous deux s'y rendent fréquemment pour des chasses, des revues ou des promenades. Le 21 août 1719, le 
chevalier de Pezé, gentilhomme de la manche et capitaine des gardes françaises est nommé gouverneur de cette résidence pour assurer la sécurité du roi. Le tableau de M. P. Denis témoigne de ces visites ${ }^{50}$. Un manège et une ménagerie y sont aménagés. Le 15 novembre 1720, Maréchal porte ce point au crédit de Fleury qui " imagine de faire travailler le roi à la Muette au bois de Boulogne, pour compenser par une promenade l'ennui de l'étude " ${ }^{51}$. Le lieu commun utilisé par Maréchal paraît bien réducteur au regard des luttes d'influence auprès du jeune garçon.

Si Fleury reste le précepteur qui instruit le roi le matin et en fin d'aprèsmidi, à partir de 1718 le nombre de versions latines diminue de manière importante (et cela ne peut pas être attribué à un défaut de conservation des documents). Un autre indice nous alerte. C'est la fin brutale de l'Abrégé d'histoire de France rédigé pour Louis XV. Pourquoi s'arrête-t-il à l'année 987, sans suite ni conclusion?

Pourtant, dans la première lettre en latin de Fleury au pape, datée de la première moitié de 1717, Fleury prétend qu'il " tient prête une histoire de nos rois dans laquelle il [Louis XV] puisse regarder, comme dans un miroir, de grands exemples de toutes les vertus depuis le roi Clovis à nos jours " ${ }^{52}$. Une histoire de Clovis à nos jours? Or le manuel de Fleury retrace l'histoire de France de Pharamond à la fin de la deuxième race (en 987). Ne serait-ce pas la preuve que Fleury envisageait une suite en 1717? Si l'Abrégé d'histoire de France est utilisé jusque-là (Fleury parle au roi dans son abrégé au présent : "Vous verrez, Sire, [....] les exemples qui vous guident dans la conduite actuelle " ${ }^{53}$ ), il est bien abandonné à cette période, à la fin de la deuxième race, alors qu'une suite était envisagée sinon rédigée.

Or, nous avons une trace de ce que Fleury a enseigné à Louis XV : c'est l'important travail manuscrit sur les vertus de saint Louis, qui est achevé le

50 Tableau de Pierre Denis Martin, où l'on voit "Le Roi et le Régent arrivant à la Muette ", musée national des châteaux de Versailles et de Trianon, MV 742.

51 Gabriel Mareschal de Bièvre, Georges Mareschal, seigneur de Bièvre : chirurgien et confident de Louis XIV (1658-1736), Plon-Nourrit, 1906, p. 391.

52 Fleury écrit : "in eo jam sum ut compendiosam regium nostrorum historiam adornem, in qua ". Ranchon, dans sa biographie manuscrite du cardinal, la date du 8 juin 1717. (BnF, Naf 2076, Ranchon, fol. 169 et Naf 22405 fol. 2, papiers du cardinal de Fleury). Selon le registre des Archives du Vatican, elle est datée de mars 1717. (Archivio segreto Vaticano, Fonds Principi : no 126 à 146, puis no 207 à 248). Regarder ses vertus dans le miroir de ses ancêtres, cet usage de l'histoire comme miroir des princes a une connotation médiévale abandonnée par beaucoup à cette période qui s'interroge sur l'utilité de l'histoire. Mais le débat n'a pas lieu d'être ici.

53 Abrégé de l'histoire de France, op. cit., t. I, fol. 7. 
14 mai 1720. Une série de versions en latin qui s'interrompt, un abrégé d'histoire qui reste inachevé à une date proche du premier trimestre 1720, tout ceci indique un changement dans la nature de ce qui est enseigné. S'il est difficile d'en donner les raisons, on peut en mesurer les conséquences sur le personnel employé.

Les premiers changements de personnel commencent par la mise à l'écart d'un sous-précepteur, Vittement. Au prix de la proposition d'une abbaye, dont il déclina l'offre, refusant le paiement d'une mise à l'écart sans bruit, Vittement se retire en 1719. Alary est nommé sous-précepteur et entre en service en mars $1720^{54}$. Qui de Fleury ou du Régent a choisi de nommer un homme jeune (29 ans) et dynamique, selon les gens qui le connaissent? Les changements de ce type sont suffisamment rares en cours d'éducation pour que celui-ci étonne.

Jeune ambitieux, Alary a réussi malgré ses modestes origines familiales. Soutenu par les Dangeau, il appartient à un groupe informel d'érudits et de géographes. Il a servi de secrétaire à l'abbé de Longuerue au moment où celui-ci travaille avec Guillaume Delisle et Jean-Baptiste Bourguignon d'Anville (22 ans) qui dessine des cartes pour le livre de celui-ci ${ }^{55}$. Les écrits pédagogiques de d'Anville sont encore à analyser ${ }^{56}$. Il fréquente les salons parisiens à cette date.

Doit-on voir un parallèle entre la nomination d'Alary et la diminution des versions latines? Doit-on voir un lien entre le choix d'Alary et l'abandon de l'Abrégé de l'histoire de France? Tout me porte à le croire sans que je puisse y apporter de preuves. On ne peut d'abord que s'interroger sur le fait que, au moment où le précepteur qui a rédigé cet abrégé important en taille et qui a nécessité de lourdes recherches, au moment où l'histoire devient une matière essentielle dans les études du jeune roi, le précepteur en titre soit doublé par un jeune sous-précepteur inconnu.

Ce qui motive ce changement est certainement le constat que le temps imparti pour l'éducation de Louis XV est désormais court. Il reste deux à trois ans avant la majorité, il faut être efficace et pragmatique. Louis XV ne pourra devenir l'excellent historien que furent son grand-père et son père, ayant chacun bénéficié d'une période d'éducation beaucoup plus longue. Le roi-mineur

54 Nicolas Clément, L'abbé Alary (1690-1770), Paris, H. Champion, 2002.

55 Son premier protecteur fut l'historien Louis du Four, abbé de Longuerue (1652-1733) qui publia en 1719 une Description historique et géographique de la France ancienne et moderne.

56 Voir le colloque international qui sera consacré au géographe français Jean-Baptiste d'Anville (16971782) à la Bibliothèque nationale de France, 20 et 21 septembre 2012. En ligne : <http://danville. hypotheses.org/>. 
cesse à cette période les visites des cabinets de physique ou des églises de la capitale. Il peut encore parfaire son latin et son histoire, mais il faut surtout lui apprendre à régner.

Avec Alary, Louis XV aborde un apprentissage pratique, concret et qui se veut efficace. Alary commence ses premières leçons par la généalogie et l'art du blason, à l'aide des recueils rassemblés par l'abbé Louis Dangeau (1643-1723). Complétant les connaissances acquises sur le grand Armorial de Chevillard ${ }^{57}$, réalisé pour lui, cet apprentissage concret d'un art de Cour à usage immédiat permet au roi de connaître les familles de la Cour et les relations entre elles. De même, à cette date sont réalisées par Delaistre les superbes planches ${ }^{58}$ des régiments, de façon à ce que le roi identifie très rapidement les corps d'armées.

Le roi abandonne les textes religieux comme base des versions latines pour découvrir, nouvelle perspective pour lui, l'Antiquité. Guillaume Delisle utilise le goût du roi pour les cartes en lui représentant la retraite des Dix mille, imprimée en octobre 1723, ou les empires de Darius ${ }^{59}$. Entre 1722 et 1723 , le roi travaille l'argumentation et la rhétorique dans des versions tirées de la vie des grands hommes de l'Antiquité ${ }^{60}$. Il réutilise des extraits des travaux et des fables de Fénelon.

Le Régent développe l'enseignement militaire de Louis XV (douze ans) dès l'été 1722, notamment par un entrainement grandeur nature dans le camp militaire de Montreuil organisé par son sous-gouverneur Pezé. D’ailleurs à cette date interviennent les nouveaux sous-précepteurs que sont François Chevallier, maître de mathématique chevronné dont l'oncle Joseph Sauveur était maître de mathématique du duc de Bourgogne, et surtout le vieux maré-

57 J. Chevillard, Grand Armorial, s.l.n.d,. in-fol, 2 vol., BnF, Réserve des livres rares velin-25. Ces deux livres figurent dans l'inventaire manuscrit de la bibliothèque du roi en 1730 , BnF, Naf 320 , section E, Arts et mathématiques, fol. 22, n 9 et 10 en compagnie de Cartes de blason de chronologie et d'histoire de 1699, 1702.

58 Archives de l'armée de terre, Vincennes, pour les carabiniers (A1 J11), pour les gendarmes (A1J10 en 1 tome), une copie des gendarmes et des carabiniers (AlJ10 en 3 tomes), et un recueil des machines de guerre (A1G793).

59 Un grand volume comportant ces cartes se trouve à la bibliothèque municipale de Versailles (grand folio RES I 86 a), comme l'Atlas de Guillaume Delisle de 92 pages qui regroupe les cartes de Guillaume Delisle de 1700 à 1726 . Les cartes d'histoire sont situées p. 80 et suiv. Cette série comporte la retraite des Dix Mille, (imprimée le $1^{\text {er }}$ octobre 1723), l'empire d'Alexandre, celui de Darius, celui de l'empire d'Orient sous Constantin Porphyrogénète d'après son livre de l'administration impériale, (fol. 89), celui de la Rome " dans sa plus grande étendue " et des cartes de France " tant sous les Romains que sous les trois races des rois".

60 BnF, msfr 2323, version et apophtegmes 1722/1723. 
chal de Puységur, théoricien succédant à Vauban, qui assure des conférences de pratique militaire.

La modification de l'équipe s'accompagne donc d'une réelle modification du contenu de l'éducation. Fleury prend-il de la hauteur par rapport à l'emploi de précepteur, en déléguant l'apprentissage quotidien à de jeunes ambitieux et compétents? Une telle organisation, fondée sur une délégation au sousprécepteur, se retrouve dans d'autres éducations, comme celle de Huet pour le grand dauphin et de Claude Fleury pour le duc de Bourgogne. Cette réponse ne suffit cependant pas.

\section{3 - Le rôle déterminant du Régent au cours des derniers mois de formation}

L'année du sacre, en 1722, les changements s'accélèrent, le Régent impose son choix : il poursuit insensiblement la modification du système rigide hérité de 1715 afin qu'il se perpétue. Il lui faut achever la question de la communion du roi, évoquée précédemment, l'apprentissage d'un certain nombre de connaissances, et la transmission du pouvoir politique, dernier aspect de l'éducation d'un roi. Quels hommes peuvent remplir ce programme?

Qui va assurer la communion du roi à Pâques 1722 ? Le jeudi 31 juillet 1721 , le roi a un malaise à la messe dans sa paroisse à Saint-Germainl'Auxerrois et il est malade jusqu'au 6 août. C'est l'occasion d'une nouvelle querelle. Dodart premier médecin hésite sur le diagnostic mais Helvétius, médecin ordinaire du roi, ami du Régent, donne fermement son avis.

L'autre clan trouve enfin l'occasion d'attaquer. Madame de la Ferté, sœur du duc et de la gouvernante, amie de Villeroy, dénonce un empoisonnement, de manière à mettre en cause le duc d'Orléans. Villeroy acquiesce et met en branle toute la procédure thaumaturgique. Il fait ouvrit la châsse de sainte Geneviève et ordonne une prière de quarante heures. Le 3 août, il va à la messe à Notre-Dame avec toute sa famille et fait distribuer de l'argent. Un Te Deum est chanté à la Sainte-Chapelle. Villeroy en profite pour se réconcilier avec les membres du parlement. Il leur offre la possibilité de rendre visite au roi alors même que les grandes entrées ont des difficultés pour entrer dans la chambre du roi. L'annonce de la guérison du roi déclenche une explosion de joie suivie d'une fête et de feux de joie organisés par Villeroy pendant plusieurs jours. Il tente de rendre encore plus belle la fête de la saint Louis. Le roi, à peine remis, appréhendant la foule, se cache dans les coins aux Tuileries, quand Villeroy 
le tire par la manche et lui dit " tout cela est à vous et vous appartient, vous êtes le maître ". Cette phrase est portée au discrédit du duc par une grande partie des mémorialistes (aucun ne la replaçant dans le contexte) qui n'y voient qu'une manière pour le gouverneur de se faire valoir, de justifier de sa victoire sur la maladie devant le peuple de Paris.

Alors que les relations sont très tendues entre le gouverneur Villeroy et le Régent, celui-ci se décide à agir dans le dernier trimestre de 1721. Le Régent, pour diverses raisons, est momentanément favorable aux jésuites contre Noailles. Les jésuites en profitent pour récupérer l'emploi de confesseur qui leur a échappé en 1716. Le confesseur Claude Fleury reçoit en mars 1722 le discret conseil de se retirer. Il est remplacé par le père Bertrand Claude Taschereau de Linières, directeur de conscience de la mère du Régent.

Mais ceci provoque un veto de la Vieille Cour, le cardinal de Noailles se refusant à recevoir Linières. Malgré la pression de André-Hercule de Fleury, rien n'y fait. C'est pourquoi le roi s'installe à Versailles vers le $1^{\mathrm{er}}$ mai 1722 . Ce choix apporte la solution à trois problèmes : il permet de célébrer la première communion du roi à Saint-Cyr (diocèse de Chartres), en dehors du diocèse de Noailles; il donne l'occasion de s'éloigner de Paris où " le public ne fera pas quatre bonnes lieues pour venir réclamer les papiers [de Law] " ${ }^{61}$; il offre enfin au Régent la possibilité d'agir contre la Vieille Cour sans qu'elle fasse appel au soutien populaire parisien.

L'attaque contre les Noailles commence le 19 juin $1722^{62}$, celle contre Villeroy, par l'intermédiaire de sa petite-fille ${ }^{63}$, a lieu fin juillet 1722 , avant l'éclat final contre un Villeroy qui ne voit rien venir au début d'août. Le lundi 10 août 1722, Villeroy (quatre-vingts ans) est donc arrêté par le marquis de la Fare (capitaine des gardes du Régent), puis confié à d'Artagnan, sur un ordre signé du jeune roi. "Voilà comment on le récompense des soins pour l'éducation

61 Le correspondant à Paris du roi de Prusse, Chambrier est extrêmement bien informé de la situation de la Cour ces années-là. Archives du ministère des Affaires étrangères, fonds des Correspondances politiques, fonds Prusse, Chambrier, 70, mai 1722.

62 Le Régent a d'autres griefs contre eux. Noailles a soutenu les revendications des ducs et pairs contre " ce faquin de Dubois ". Il a soutenu d'Aguesseau contre le roi alors que Villeroy préférait se taire. Il organise des réunions de mécontents à Saint-Germain et chez sa sœur, la marquise de la Vallière. Ces partisans de l'Espagne souhaitent voir régner le duc du Maine. Et dernier argument, le duc de Noailles sera capitaine des gardes du roi de quartier à la majorité du roi et le Régent craint qu'il n'en profite pour l'arrêter.

63 Sa petite-fille, la duchesse de Retz et son petit-fils, le marquis d'Allincourt sont renvoyés de la Cour pour conduite légère. Fleury le dissimula au jeune Louis XV en disant que " ce sont des jeunes gens qui ont arraché des palissades ". 
et la conservation de la santé du roi. [...] Ce sont les premiers fruits du voyage à Versailles. Ce coup aurait été plus risquable à Paris, où le peuple aime et respecte le maréchal "64.

Il reste Fleury. Celui-ci doit son élévation aux Noailles et à Villeroy. Depuis deux ans, il est mis sur la touche par Alary qui a réorienté les études. Fleury décide de jouer son va-tout politique en exerçant un chantage affectif sur le jeune roi, afin de prouver qu'il n'est pas lié à Villeroy. Il ne se présente pas à l'heure de l'étude. Le roi le fait chercher. Il a disparu. Le roi demande s'il n'est pas allé "à Villeroy, ou à Sceaux voir le duc du Maine, ou à Paris voir Madame de Lévis qu'il savait être de ses amis. Ces questions firent faire bien des réflexions de la part d'un enfant qu'on n'était point accoutumé d'entendre parler " ${ }^{65}$. Louis XV, à douze ans, a parfaitement pris la mesure du réseau de Fleury et révèle une grande profondeur d'analyse politique.

Le précepteur entend montrer qu'il dépend du roi seul et non du Régent, puisque c'est sur une lettre du roi qu'il accepte de revenir. Seul le roi peut le rappeler et Barbier d'ajouter : Fleury est " un homme de beaucoup d'esprit, et ce coup est d'une grande politique. Il a mis le Régent hors d'état de l'exiler à présent, aussi Monsieur le Régent en a-t-il été très chagrin "66. Voilà comment Fleury n'a pas été renvoyé alors que son rôle de précepteur du roi l'occupe de moins en moins. À la place du gouverneur Villeroy, est nommé le duc de Chârost, commandant de la compagnie des Gardes du corps du roi. Chârost assure juste la protection du jeune roi, ce qui est réduire l'emploi de gouverneur d'un roi à peu de chose. Désormais, on assiste à une redistribution des rôles dans l'équipe éducative, à une complémentarité plus forte entre le Régent et Fleury.

Si on ne sait pas exactement quelle activité éducative exerce Fleury à cette période, on pourrait émettre l'hypothèse suivante sur son nouveau rôle, d'après les modifications auxquelles on assiste à la Cour. En effet, le Régent connait les qualités de jugement et de discernement de Fleury. Le précepteur est alors l'un des hommes les plus capables de montrer au roi l'art concret des négociations voire de la conciliation à la Cour. Et il les applique effectivement à l'égard des courtisans. Ainsi le maréchal de Villars, si l'on en croit ses

64 Edmond Jean François Barbier, Chronique de la régence et du règne de Louis XV (1718-1763), Paris, Charpentier, 1857, t. I, p. 153.

65 Charles-Jean-François Hénault, Mémoires du président Hénault, Paris, E. Dentu, 1855, appendice, p. 351.

66 Edmond Jean François Barbier, op. cit., t. I, p. 235. 
Mémoires, marque son étonnement à l'intérêt subit que le roi lui porte. En effet, Louis XV insiste pour qu'il participe à son jeu, au brelan, deux fois par jour à Versailles; il demande plusieurs fois à ce maréchal de France de venir assister à l'entraînement de la prise du fort de Montreuil, qui mobilise toute la Cour et l'armée pendant les deux mois de l'été 1722. L'hypothèse serait la suivante : ces jeux, cette insistance à forcer les maréchaux et la haute noblesse à faire leur cour au jeune roi, ne préfigurent-ils pas l'instauration des entrées familières, des petits soupers, mode de gouvernement que Fleury va mettre au point dès les années 1723-25? Et l'on peut ainsi se demander si le Régent n'utilise pas Fleury comme organisateur de l'emploi du temps du roi et organisateur des activités de la Cour? Le gouverneur est renvoyé, mais Fleury excelle dans ce type d'emploi et les sous-précepteurs font son travail, tandis que le Régent initie politiquement le jeune roi au gouvernement.

En effet, le Régent passe de plus en plus de temps auprès du roi. Le roi était entré au Conseil, comme le prévoyait le testament de Louis XIV, le 18 février 1720, " non pour décider mais pour entendre et prendre les premières connaissances des affaires ". Plusieurs jours par semaine, le Régent prend en main l'apprentissage concret du métier de roi. Il lui montre " la distribution d'emplois vacants, de bénéfices, de certaines magistratures, d’intendances, de récompenses de toutes sortes et de lui expliquer en peu de mots les raisons des choix et des préférences, quelquefois des distributions de finances, enfin les premières nouvelles étrangères, quand il y en avoit à sa portée, avant qu'elles ne devinssent publiques "67.

Des conférences, qu'on appellerait de sciences politiques, sont faites. Alary y participe comme spécialiste de l'Allemagne, Dubois communique les textes qu'il avait fait rédiger pour le Régent, tout cela est joint aux Mémoires des intendants pour le duc de Bourgogne commandé par Beauvillier. M. Le Dran, chef du dépôt des Affaires étrangères du Louvre rédige 21 études sur les relations entre les États ${ }^{68}$. Les Mémoires lus en 1722 comportent notamment des notions d'économie ${ }^{69}$. Cette préoccupation nouvelle pour un prince est de la responsabilité du Régent, attentif à faire comprendre au roi les revenus, les

67 Saint-Simon, éd. Coirault, op. cit., t. II, p. 490-493.

68 Archives des Affaires étrangères. Mémoires et documents, France.

69 BnF, Naf 22109, Mémoires qui furent lus le 26 août 1722 devant le roi pour l'instruction de Sa Majesté dans les différentes affaires du gouvernement, rédigé par Monglas, 84 p. (papiers de Lefebvre d'Amécourt). 
amortissements, la complexité des différents impôts royaux et seigneuriaux, les droits de transmission, le détail des fermes, des douanes.

En vue du sacre, le roi étudie les recueils d'estampes des sacres. Bourguignon d'Anville rédige pour lui une dissertation historique sur les douze pairs de France et leur rôle lors du sacre ${ }^{70}$. En octobre 1722, le roi aborde des entretiens sur les questions militaires, assortis de statistiques. Le duc de Bourgogne avait eu cette formation vers l'âge de treize ans. Il est impossible d'attendre pour Louis XV. À treize ans, il sera roi et les études cesseront devant l'abondance des activités. Ces années-là (1720-1722), le Régent a déterminé fortement l'éducation du roi Louis XV.

Après la présentation des hommes choisis par Louis XIV pour l'éducation de son successeur, la chronologie fine des modifications des équipes et du contenu de l'éducation permet de dégager la réorientation et la réorganisation progressive de l'éducation de Louis XV. La Vieille Cour a débuté une éducation reproduisant la formation à l'ancienne du dauphin. Mais le Régent agit de façon à modifier ce modèle éducatif initialement prévu. L'année 1722 constitue indiscutablement un tournant dans la formation du roi : année de sa communion, année d'initiation politique et des premières présences aux conseils, année de préparation de son sacre. Sa majorité approche (février 1723). Le " coup d'État éducatif " pacifique de l'année 1722 n'est pas la moindre des réussites du Régent. Les matières enseignées ont été considérablement modifiées, les hommes ont changé par une série de renvois sans remous. Les rôles se sont inversés. Ainsi le surintendant ne parvint pas à exercer une grande influence. Le gouverneur qui a transmis la représentation du comportement monarchique s'efface devant le précepteur qui est appelé à enseigner d'autres savoirs et comportements au jeune roi, obtenant ainsi une place politique qu'aucun autre précepteur n'a eue jusqu'alors. Le Régent s'impose comme étant l'homme qui transmet directement l'imperium. Il donne au roi un apprentissage pratique du pouvoir en l'y associant, tout comme l'avait fait Mazarin avec Louis XIV.

À ce moment important de l'éducation du roi qu'est l'apprentissage de l'exercice du pouvoir, il est sûr que de tels changements auprès d'un jeune

70 BnF, Naf, fol. 17382 dans Papiers relatifs à l'histoire de France de Jean-Baptiste Bourguignon d'Anville: Dissertation historique sur les douze pairs de France au sacre de nos rois, 1722. 
homme aussi sensible que Louis XV n'ont pu que laisser des traces et lui donner concrètement une leçon de diplomatie de Cour et de gouvernement.

Pascale MORMICHE Université de Cergy-Pontoise, États, Société, Religion - EA 2449 pascale.mormiche@free.fr 